\title{
Localisation of Xp21 meiotic exchange points in Duchenne muscular dystrophy families
}

\author{
CORLEE J BERTELSON* $\dagger$, JAMES A BARTLEY \\ ANTHONY P MONACO $§$, CHRIS COLLETTI-FEENER, , \\ KENNETH FISCHBECK\|, AND LOUIS M KUNKEL +9 \\ From * the Department of Biology, Brandeis University, Waltham, MA; †Mental Retardation Center and \\ Division of Genetics, The Children’s Hospital, Boston, MA; $¥$ Division of Medical Genetics, University of \\ Iowa, Iowa City, IA; \$Program in Neuroscience, Harvard University, Cambridge, MA; |Department of \\ Neurology, The Universtiy of Pennsylvania, Philadelphia, PA; and $\llbracket$ Department of Pediatrics, Harvard \\ Medical School, Boston, Massachusetts, USA.
}

SUMmaRY The inheritance of Duchenne muscular dystrophy in 25 families was studied with $13 \mathrm{X}$ chromosome specific cloned DNA fragments from 10 loci in and surrounding Xp21. When multiple probes were informative, the meiotic exchange points for each meiosis were located in individual families. Neither genetic nor physical evidence indicates an unusually high recombination rate across $\mathrm{Xp} 21$ in these 25 families.

Duchenne muscular dystrophy (DMD) is an $\mathrm{X}$ linked human genetic disorder with a frequency of one in 4000 live male births. In recent years 12 females have been described with phenotypes similar to DMD and each of these females was found to be a carrier of a balanced $\mathrm{X}$; autosome translocation involving the $\mathrm{Xp} 21$ region of the human $\mathrm{X}$ chromosome. ${ }^{1}$ Several patients with deletions of the Xp21 region and the associated DMD phenotype have also been described. ${ }^{2-5}$ Formal genetic linkage analysis in DMD families, in addition to the physical $\mathrm{X}$ chromosomal abnormalities cited above, supports evidence that the DMD locus resides in Xp21.67 However, while physical and genetic data clearly locate DMD in Xp21, a close cloned marker locus DXS164 (pERT87), which is able to detect microdeletions in DMD patients, ${ }^{8}$ is still an appreciable genetic distance from certain DMD mutations. ${ }^{9} 10$

Recently, the idea has been proposed that there might be an increased frequency of meiotic exchange within or nearby the DMD locus. ${ }^{11}$ To test this hypothesis, $13 \mathrm{X}$ chromosome specific cloned DNA sequences from 10 loci surrounding or within $\mathrm{Xp} 21$ were used to follow the inheritance of DMD in 25 families. The meiotic exchange points in these 25 families were mapped for the Xp21 region. The physical relationship of the various loci relative to one another was determined by mapping the 13 cloned DNA fragments versus $\mathrm{X}$; autosome trans-

Received for publication 25 May 1986.

Revised version accepted for publication 4 August 1986. locations and cytologically detectable deletions. Two of the previously published cytologically detectable deletions have been estimated to be missing between 10 and 20 million base pairs of DNA, ${ }^{12} 13$ allowing for the assignment of approximate relative distances between the cloned DNA loci within this region. The incidence of meiotic exchange within the region of approximately 20 million base pairs of DNA using these 13 cloned loci does not indicate an unusually high recombination rate in $\mathrm{Xp} 21$ for the 25 families studied.

\section{Materials and methods}

PATIENTS AND FAMILIES

Twenty-five DMD families with one or more affected males and obligate carrier females were studied. Diagnosis of DMD was based on standard criteria: family history of DMD, clinical examination, blood enzyme levels (including CK), muscle biopsy, and other laboratory tests. ${ }^{14}{ }^{15}$ Fifteen of the 25 families were obtained from The Children's Hospital, Boston, the MDA Portland, Maine, or the Center for Human Genetics, Bar Harbor, Maine. Nine families were obtained from the University of Pennsylvania. One family was provided by Dr Jean Amos of the Shriver Center, Waltham, Massachusetts.

DNA ISOLATION, RESTRICTION ENZYME CLEAVAGE, AND SOUTHERN BLOTTING

Human DNA was isolated from whole blood 
leucocytes. ${ }^{16}$ Human DNA (3 $\left.\mu \mathrm{g}\right)$ was digested to completion under conditions recommended by the manufacturer for each particular restriction enzyme. DNA concentrations were determined using the DNA specific fluorescent dye 4', 6-diamidino-2phenylindole (DAPI $)^{17}$ and measured on a fluorescence spectrophotometer (Perkin-Elmer). DNA $(1 \mu \mathrm{g})$ was loaded per lane onto $0.7 \%$ horizontal agarose gels and DNA fragments were separated by electrophoresis according to molecular weight. Following denaturation and renaturation, DNA was transferred ${ }^{18}$ onto nitrocellulose membranes (Schleicher and Schuell).

\section{PROBES}

The cloned DNA fragments used as hybridisation probes were isolated either from plasmid subcloned inserts or from subfragments of whole phage inserts released from their vectors by digestion with the appropriate restriction enzyme. Except for the probe OTC, where the oligonucleotide primed radiolabelling technique was used, ${ }^{19}$ all the cloned DNA fragments were ${ }^{32} \mathrm{P}$ radioactively labelled using the enzyme T4 DNA polymerase. ${ }^{20}$ With the exception of $\mathrm{C7}$, prehybridisation of nitrocellulose filters was at $45^{\circ} \mathrm{C}$ in $50 \%$ formamide, $4 \times \mathrm{SSC}, 0.05$ mol/l sodium phosphate buffer (pH 6.8), 8\% dextran sulphate, $10 \times$ Denhardt's, $100 \mu \mathrm{g} / \mathrm{ml}$ transfer RNA, $25 \mu \mathrm{g} / \mathrm{ml}$ sheared salmon sperm
DNA, $\mathbf{0} \cdot 1 \%$ SDS, and $1 \mathrm{mmol} / \mathrm{l} \mathrm{EDTA}$ for six to 12 hours. $\mathrm{C} 7$ was prehybridised at $68^{\circ} \mathrm{C}$ in $4 \times \mathrm{SSC}$, $0.05 \mathrm{~mol} / \mathrm{l}$ sodium phosphate buffer $(\mathrm{pH} 6 \cdot 8), 5 \%$ dextran sulphate, $2 \times$ Denhardt's, $100 \mu \mathrm{g} / \mathrm{ml}$ tRNA, $25 \mu \mathrm{g} / \mathrm{ml}$ sheared salmon sperm DNA, $0 \cdot 1 \%$ SDS, and $1 \mathrm{mmol} / \mathrm{l}$ EDTA. Hybridisation of nitrocellulose filters was under the same conditions as prehybridisation using fresh solution with the addition of 0.5 to $1.0 \times 10^{6} \mathrm{cpm} / \mathrm{ml}$ radiolabelled DNA to the hybridisation solution and hybridised for 16 to 20 hours. Nitrocellulose filters were washed in $0.1 \%$ SDS, $0.1 \times$ SSC several times at room temperature and at $55^{\circ} \mathrm{C}$ for one hour Autoradiography was at $-70^{\circ} \mathrm{C}$ on X-OMAT film with a Du Pont intensifying screen for one to seven days.

\section{Results}

The 10 independent cloned loci examined all reside within or near Xp21 and DMD. Many of these cloned loci have previously been mapped relative to various translocation breakpoints in $\mathrm{Xp}^{11} 12162122$ and to patients with Xp deletions. ${ }^{2}{ }^{12}{ }^{22}$ Here, we present a further delineation of the physical map by testing the DNA of four patients with glycerol kinase (GK) deficiency ${ }^{4}$ for presence or absence of the 10 cloned loci. In addition to the GK deficient patients, results are presented for DNA isolated from series of other interstitial deletion samples and

TABLE 1 Physical ordering of Xp21 loci using the DNA of patients with cytologically detectable deletions and X;autosome translocations.

\begin{tabular}{|c|c|c|c|c|c|c|c|c|c|c|c|}
\hline \multirow[t]{3}{*}{ Probe } & \multicolumn{11}{|c|}{ Hybridisation results } \\
\hline & \multicolumn{7}{|c|}{ Human DNA samples } & \multicolumn{4}{|c|}{ Rodent-human hybrids } \\
\hline & 2470 & $K C$ & $B B$ & $R U S$ & $R O N$ & $T J$ & $M I C$ & $E D N$ & $B 12$ & 617 & 422 \\
\hline $\mathrm{L} 1 \cdot 28(D X S 7)$ & - & + & + & + & + & + & + & NT & + & + & - \\
\hline OTC (OTC) & - & - & + & + & + & + & + & NT & + & + & - \\
\hline pERT145 (DXS14I) & - & - & - & + & + & + & + & NT & + & + & - \\
\hline $754(D X S 84)$ & - & - & - & - & + & + & + & NT & + & - & - \\
\hline pERT84 (DXS142) & - & - & - & - & + & - & + & + & + & - & - \\
\hline pERT87 (DXS164) & - & - & - & - & + & - & - & + & - & - & - \\
\hline J-Bir & - & - & + & - & + & - & - & + & - & - & - \\
\hline C7 (DXS28) & - & - & + & + & - & + & - & NT & - & - & - \\
\hline $99-6(D X S 41)$ & - & + & + & + & + & + & + & NT & - & - & - \\
\hline $\mathrm{D} 2(D X S 43)$ & + & + & + & + & + & + & + & NT & - & - & - \\
\hline \multicolumn{12}{|c|}{ 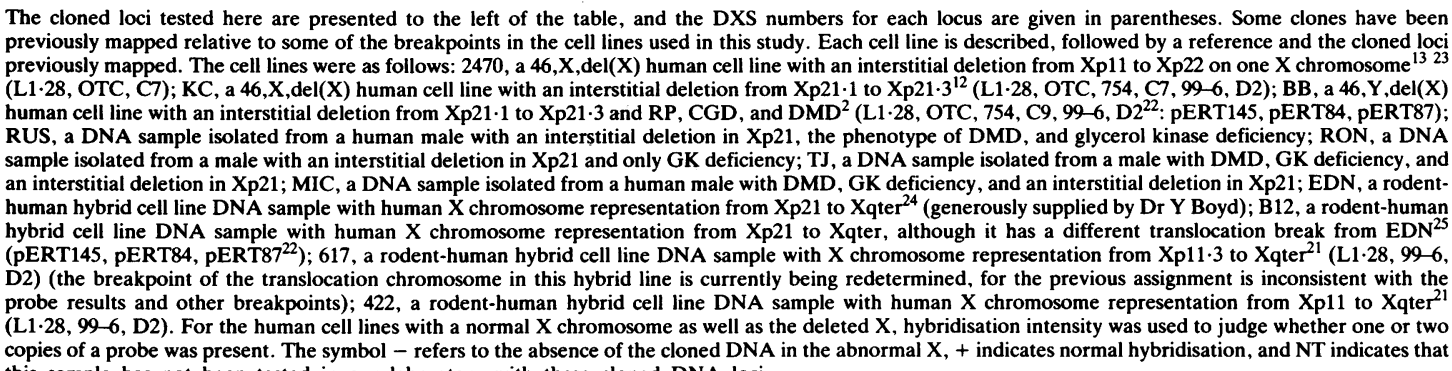 } \\
\hline
\end{tabular}


from rodent-human hybrid cell lines with different representation for sections of the human $\mathrm{X}$ chromosome. All 10 cloned sequences were hybridised to a panel of these DNA samples and the results are presented in table 1 . The hybridisation results are indicated by absence $(-)$ or presence $(+)$ of the cloned sequences in the various patient or hybrid cell line DNA samples. In cases where a normal X was also present in a cell line, absence or presence was judged by hybridisation intensity similar either to that of a normal female or a normal male. An interpretation of the results indicates the following order of separable loci: pcen-L1.28-OTCpERT145-754-pERT84-pERT87-J-Bir-C7-99.6D2-pter.

Each locus mapped in table 1 detects the informative restriction fragment length polymorphism (RFLP ${ }^{26}$ ) alleles presented in table 2. The allele frequencies for each probe-enzyme combination are given with the observed heterozygosity at each locus in the 25 families studied here. pERT87-1, pERT87-8, pERT87-15, and pERT $87-30$ are separate subcloned fragments mapping in the same $112 \mathrm{~kb}$ region and can therefore be considered for linkage analysis as tightly linked markers from within the same locus. $\mathrm{J}$-Bir is in close proximity to the pERT87 clones at

TABLE 2 Cytogenetic location and polymorphism description of each of the human X chromosome cloned DNA fragments.

\begin{tabular}{|c|c|c|c|c|c|}
\hline $\begin{array}{l}\text { Cloned } \\
\text { DNA } \\
\text { fragment }\end{array}$ & Location & $\begin{array}{l}\text { Restriction } \\
\text { enzyme }\end{array}$ & $\begin{array}{l}\text { Allele } \\
\text { sizes }(p / q)\end{array}$ & $\begin{array}{l}\text { Rare allele } \\
\text { frequency }(q)\end{array}$ & $\begin{array}{l}\text { Observed } \\
\text { hetero- } \\
\text { zygosity } \\
(\%)\end{array}$ \\
\hline $\mathrm{L} 1 \cdot 28$ & $\mathrm{Xp} 11 \cdot 3$ & TaqI & $16 / 12$ & 0.32 & 39 \\
\hline OTC & Xp21.1 & MspI & $6 \cdot 6 / 6 \cdot 2$ & 0.39 & 58 \\
\hline \multirow[t]{2}{*}{$145-12$} & $\mathrm{Xp} 21 \cdot 1$ & TaqI & $3 \cdot 7 / 4 \cdot 8$ & 0.23 & 36 \\
\hline & & MspI & $4 \cdot 8 / 18$ & 0.22 & 16 \\
\hline 754 & $\mathrm{Xp} 21 \cdot 2$ & PstI & $18 / 13$ & 0.38 & 65 \\
\hline $84-10$ & $\mathrm{Xp} 21 \cdot 2$ & TaqI & $4 \cdot 5 / 2 \cdot 6$ & $0 \cdot 17$ & 20 \\
\hline $87-30$ & $\mathrm{Xp} 21 \cdot 3$ & $B g / I I$ & $30 / 7 \cdot 7$ & 0.33 & 24 \\
\hline \multirow[t]{3}{*}{$87-15$} & $\mathrm{Xp} 21 \cdot 3$ & $X m n I$ & $1 \cdot 6,1 \cdot 2 / 2 \cdot 8$ & $0 \cdot 32$ & 29 \\
\hline & Xp21.3 & TaqI & $3 \cdot 1 / 3 \cdot 3$ & 0.33 & 57 \\
\hline & $\mathrm{Xp} 21 \cdot 3$ & Bam HI & $7 \cdot 1,2 \cdot 3 / 9 \cdot 4$ & 0.38 & - \\
\hline \multirow[t]{2}{*}{$87-8$} & Xp21.3 & Bst XI & $4 \cdot 4 / 2 \cdot 2$ & 0.40 & 42 \\
\hline & Xp21.3 & TaqI & $3 \cdot 8 / 1 \cdot 1$ & 0.29 & 47 \\
\hline \multirow[t]{2}{*}{$87-1$} & $\mathrm{Xp} 21 \cdot 3$ & $X m n I$ & $8 \cdot 7 / 7 \cdot 5$ & 0.34 & 50 \\
\hline & $\mathrm{Xp} 21 \cdot 3$ & Bst NI & $3 \cdot 1 / 0 \cdot 6$ & 0.37 & 50 \\
\hline J-Bir & $\mathrm{Xp} 21 \cdot 3$ & BamHI & $5,16 / 21$ & 0.29 & 40 \\
\hline $\mathrm{C} 7$ & $\mathrm{Xp} 21 \cdot 3$ & EcoRV & $7 \cdot 5 / 8 \cdot 0$ & $0 \cdot 15$ & 29 \\
\hline $99-6$ & $\mathrm{Xp} 22$ & PstI & $23 / 13$ & 0.29 & 56 \\
\hline D2 & $\mathrm{Xp} 22$ & PvuII & $6 \cdot 0 / 6 \cdot 6$ & 0.29 & 63 \\
\hline
\end{tabular}

The cloned fragments L1.28 and 754 were provided by Professor P L Pearson of Leiden, The Netherlands. ${ }^{6} 27$ The cloned fragment OTC was provided by L Rosenberg of Yale University. ${ }^{28}{ }^{29}$ The cloned fragment $C 7$ was provided by J-L Mandel of Strasbourg, France. " The cloned fragments 99-6, D2, and the pERT87 clones were isolated in our laboratory. 816 The allele frequencies for the various loci were as previously published or calculated as part of this study. The observed heterozygosity was calculated from the proportion of women in this study heterozygous at a particular locus relative to those who were not. There were insufficient data on the BamHI alleles of $87-15$ to calculate a frequency of heterozygosity. an unknown distance towards the terminus (A P Monaco, unpublished observations), yet maps as present in the DNA of the patient $\mathrm{BB} .^{2}$ The allele frequencies for the various loci were as previously published or calculated as a part of this study. The observed heterozygosity was calculated as the proportion of obligate carrier women in this study who were heterozygous at a particular locus relative to those who were not.

DNA samples isolated from family members of women heterozygous for a particular locus were tested with the probe defining that locus. An
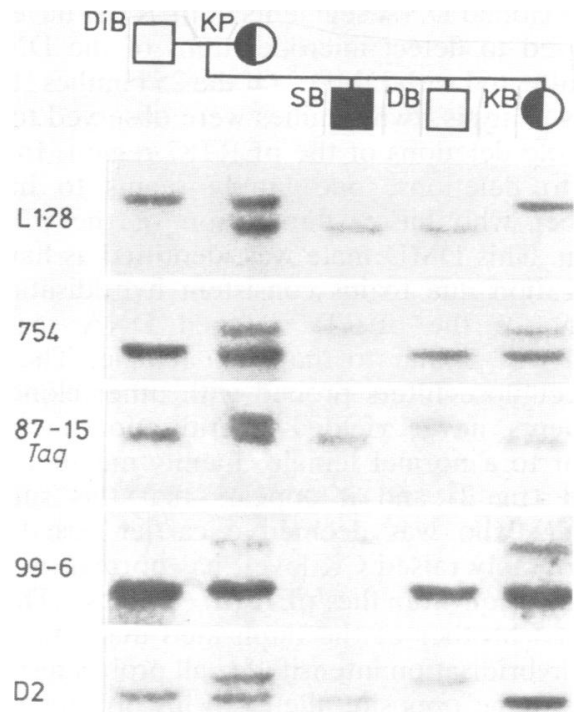

FIG 1 Segregation of five $X p$ loci in a DMD family.

$D N A$ was isolated from five members of DMD family 102. Diagnosis of DMD was according to standard criteria described in detail in Materials and methods. The mother was judged to be a carrier of the DMD mutation based on raised CK levels, previous family history, and an affected son. The daughter was judged to be a carrier of the DMD mutation based on raised CK levels. The DNA samples were cleaved with the appropriate restriction enzyme for each of the cloned DNA fragments. Gel electrophoresis, transfer, and hybridisation were as described in Materials and methods. The different loci were assessed by hybridisation with the cloned DNA fragments (from the centromere towards the terminus to the left of the figure): L1·28, 754, pERT87-15 (TaqI), 99-6, D2. The half-filled circles indicate carrier females, the filled box indicates an affected male, and the open symbols indicate the absence of the DMD mutation. Under each subject is shown the autoradiograph pattern revealing the genotype of each subject with respect to: the TaqI polymorphism of the probe L1 28 , the PstI polymorphism of the probe 754 , the TaqI polymorphism of pERT87-15, the PstI polymorphism of the probe 99-6, the PvuII polymorphism of the probe D2. 


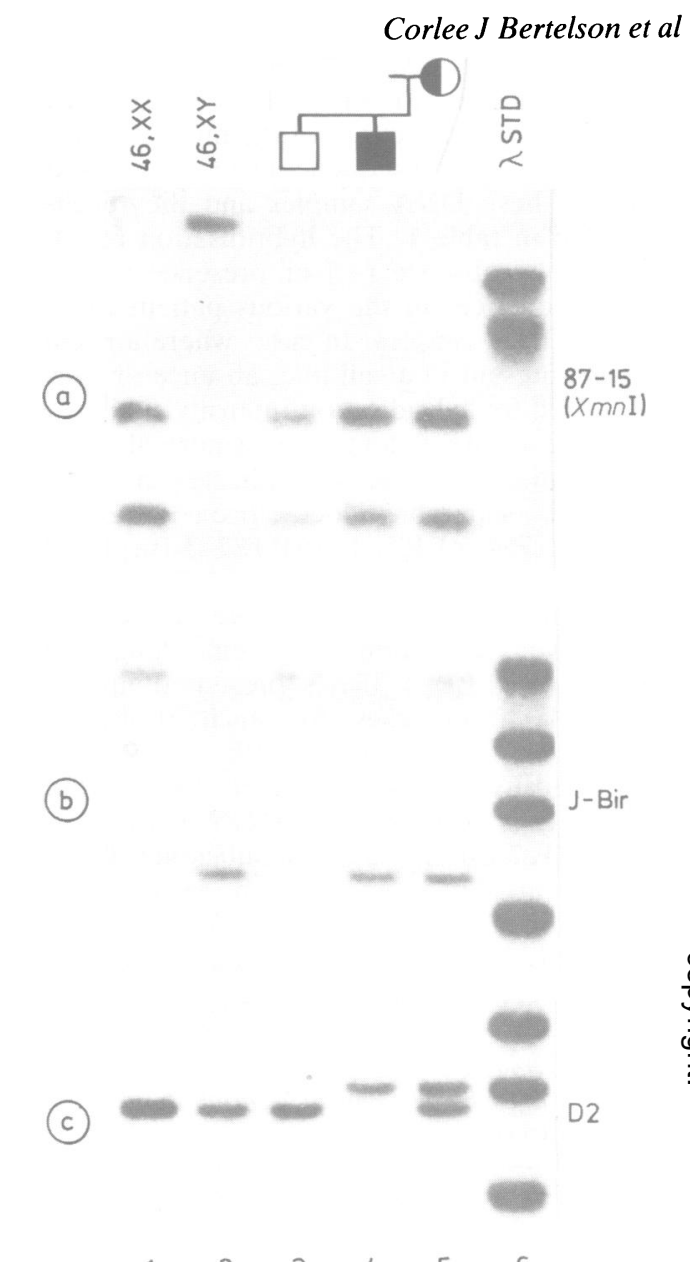

example of the segregation of alleles for five cloned DNA fragments in a particular DMD family pedigree is illustrated in fig 1 . This family shows a segregation pattern in which no recombinants are seen in three meiotic events for each of four sequences, 754, pERT87-15, 99-6, and D2, yet a fifth, L1.28, exhibits recombination (SB, fig 1). Within the distance between the cloned sequences 754 and D2 (which includes pERT87-15) there were no meiotic exchanges observed in the three possibilities. The more distant clone, L1·28, shows the single meiotic exchange point across the region in this particular family.

The cloned DNA segments of pERT87 have been observed to detect microdeletions of the DNA of boys affected with DMD. ${ }^{8}$ Of the 25 families studied in this analysis, two families were observed to have heritable deletions of the pERT87 region. In addition to deletions, one family seems to have a member who has a duplication of the pERT87 region. This DMD male was identified as having a duplication due to his consistent hybridisation intensity for the pERT87 cloned DNA segments which was similar to that of a female. The same nitrocellulose filters probed with other cloned Xp fragments never yielded hybridisation intensities similar to a normal female. Family members were tested (fig 2) and it appears that this subject's mother, who was deemed a carrier based on a considerably raised CK level, has normal two copy hybridisation for the pERT87 probes. The unaffected brother of the duplicated male has single copy hybridisation intensity for all probes tested; he also has the opposite alleles to his brother for $\mathrm{Xp}$ loci, as shown in fig 2 . The duplicated region of the DMD male appears to be large, encompassing all the pERT87 subclones (data partially shown), but not J-Bir or D2, as seen in fig 2, nor 754 (data not shown). The manner in which this duplication yields the DMD phenotype is unknown, but for both deletions and duplications these major disruptions in the region are presumably the cause of the disorder. Of interest to this study was the observation that there did not appear to be an increased or decreased frequency of recombination for surrounding loci in the two families segregating for deletions or in the one family with a male with a duplication of pERT87. In one family segregating for a deletion, there were no recombinants observed in three meioses. A second family segregating for a deletion showed a single meiotic exchange between the cloned DNA sequences C7 and D2 in three meioses. The family with the subject with a duplication of the pERT87 region exhibits one recombinant in two meioses between DMD and 145-12.

By observing the segregation of alleles for various
FIG 2 Segregation of three loci in the family of a male duplicated for the $p E R T 87$ region. DNA was isolated from a normal 46, XX female and 46, XY male and three members of DMD family 114. Diagnosis of DMD was according to standard criteria described in Materials and methods. The mother was judged to be a carrier based on raised CK levels and the birth of an affected son. All DNA samples were cleaved with the appropriate restriction enzymes for each of the cloned DNA fragments. Gel electrophoresis, transfer, and hybridisation were as described in Materials and methods. The different loci were tested by hybridisation with the cloned DNA probes listed from the centromere toward the terminus: pERT87-15, J-Bir, D2. Under each subject is shown the autoradiograph pattern revealing the genotype of each subject with respect to: the XmnI polymorphism of the probe pERT87-15; the BamHI polymorphism of the probe J-Bir; the PvuII polymorphism of the probe D2. The affected male shows normal, single copy hybridisation intensity for both the probes D2 and J-Bir. Yet, this same subject shows two copy hybridisation similar to that of his mother and the normal female for pERT87-15 (XmnI). The strong hybridisation intensity of the 46,XY male for the XmnI polymorphism of pERT87-15 is because the $1.6 \mathrm{~kb}$ and $1.2 \mathrm{~kb}$ alleles always hybridise with less intensity than the $2 \cdot 8 \mathrm{~kb}$ allele. 
TABLE 3 Recombination fractions between each of the markers analysed.

\begin{tabular}{|c|c|c|c|c|c|c|c|c|c|c|}
\hline Probe & $D 2$ & $99-6$ & $C 7$ & $J-B i r$ & pERT87 & $D M D$ & $84-10$ & 754 & $145-12$ & OTC \\
\hline $\mathrm{L} 1 \cdot 28$ & $10 / 19$ & $5 / 16$ & $1 / 1$ & $2 / 17$ & $7 / 28$ & $7 / 28$ & $1 / 4$ & $3 / 13$ & $1 / 6$ & $3 / 11$ \\
\hline OTC & $5 / 15$ & $3 / 21$ & $1 / 4$ & $0 / 8$ & $0 / 21$ & $1 / 30$ & $1 / 4$ & $0 / 12$ & $1 / 6$ & \\
\hline $145-12$ & $5 / 17$ & $2 / 12$ & $0 / 2$ & $1 / 4$ & $3 / 21$ & $3 / 21$ & $0 / 6$ & $1 / 11$ & & \\
\hline 754 & $7 / 25$ & $5 / 20$ & $1 / 6$ & $0 / 12$ & $1 / 37$ & $3 / 49$ & $0 / 4$ & & & \\
\hline $84-10$ & $0 / 4$ & $0 / 6$ & $\mathrm{NI}$ & NI & $1 / 6$ & $1 / 8$ & & & & \\
\hline DMD & $11 / 40$ & $7 / 50$ & $2 / 22$ & $1 / 22$ & $2 / 74$ & & & & & \\
\hline pERT87 & $12 / 40$ & $9 / 48$ & $2 / 22$ & $0 / 22$ & & & & & & \\
\hline J-Bir & $5 / 12$ & $1 / 11$ & NI & & & & & & & \\
\hline $\mathrm{C7}$ & $4 / 7$ & $1 / 5$ & & & & & & & & \\
\hline $99-6$ & $3 / 24$ & & & & & & & & & \\
\hline
\end{tabular}

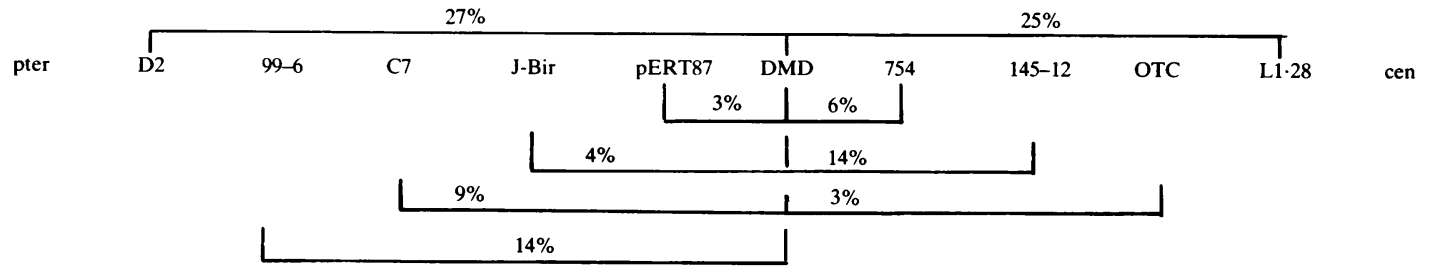

Pairwise comparison of recombination fractions between each of the cloned DNA fragments analysed when informative in the same family. The data are expressed as the number of observed meiotic exchanges between two particular loci versus the total number of informative meiotic possibilities tested. It should be noted that if, for example, a recombinant event occurs between DMD and 99-6, and if D2 is also informative in that particular family, D2 will also appear recombinant. NI indicates that no families were informative for both probes and thus no information could be obtained. Below the table is a schematic map of the probes aligned along the chromosome. Their recombination distances are derived directly from the recombination fractions between DMD and the individual cloned loci. While the genetic data on OTC seem inconsistent with its physical relationship to the loci, in the families where recombination was observed somewhere between DMD and OTC. OTC was not usually informative. There was insufficient data on 84-10 vs DMD to include it.

probe loci as presented in fig 1 and 2 , and as described above, individual crossovers were localised in all 25 families. Table 3 is a pairwise comparison of all the crossover points between two loci when both were informative in the same family, expressed as the number of observed exchanges versus the total informative meiotic possibilities. Below the table is a schematic map including the approximate distances between the separable loci. When the location of recombination exchange points were identified, the physical location of the loci, as determined by the physical mapping results presented in table 1 , was substantiated. If, for example, C7 is observed as recombinant with DMD, then the other more distal markers such as 99-6 and D2 also appear recombinant in the same person. The genetic order of loci agreed with the physical order in all instances.

The segregation of multiple cloned sequences across Xp21 through an individual family allows one to map accurately the majority of meiotic exchange points in that family. The identified exchange points can be counted to determine if there is an unusual clustering or increased incidence of exchange in a particular region when relative physical relationships between loci are known. The number of crossover events can also be calculated as the number of all meiotic exchanges observed in the region set by various loci limits for all meiotic possibilities. If the two loci limits are defined by OTC and 99-6, the meiotic exchanges between these loci can be identified, even if these particular cloned loci are not always informative in a chosen family. The cloned locus defined by pERT145, which is physically closer to 99-6 than OTC (table 1 ), might be observed to recombine in a family not informative for OTC. This exchange can still be considered to be between OTC and 99-6, despite being only detected with pERT145. In the total 87 meiotic possibilities studied here in 25 families, there were 13 exchanges mapped as physically and genetically residing between the probes $99-6$ and OTC. Increasing the physical distance, for example, to the limits set by the probes L1.28 and D2 increases the number of total observed exchanges to 27; decreasing the physical distance between loci limits decreases the number of exchanges observed. The number of observed exchange points will be a slight underestimate of the actual number of exchanges for not all probes were informative in every family.

\section{Discussion}

The physical location of several previously published cloned sequences has been implicated as being very near the mutations giving rise to 
DMD. $^{2812}$ Yet, linkage analysis of several of these probes, OTC, 754, C7, and more recently pERT87, places them from 5 to $10 \mathrm{cM}$ away from DMD. ${ }^{7} 91129$ The question of why recombination is observed in DMD families with deletion detecting probes remains unanswered. ${ }^{89}$ The clones from the $\mathrm{Xp} 21$ region appear to recombine more frequently than other regions of the genome (for example, cystic fibrosis $^{30-33}$ ), implying either that the DMD locus is very large or that the frequency of meiotic exchange in $\mathrm{Xp} 21$ is higher than in other portions of the genome. The data presented here argue against the latter explanation. In the region set by the limits of OTC and 99-6, the 13 recombinant events observed in 87 meioses corresponds to a minimum genetic distance of $15 \%$ recombination between these loci. By mapping the exchange points between OTC and 99-6, the results obtained from the small number of families in this analysis agree well with previously published data with these loci in larger, non-DMD families. ${ }^{34}$ The exact relationship between the incidence of meiotic exchange and physical distance, however, must await a complete physical map across the region. ${ }^{35}$

It is evident from previously published data and the data presented here that additional information concerning the area surrounding the Duchenne muscular dystrophy locus is important. Given the allele frequencies of the cloned loci examined, it is difficult to find many families informative for more than four cloned Xp DNA fragments. Thus, cloned DNA fragments which show multiple RFLPs with different restriction enzymes, such as the DXS164 locus, are highly valuable. It will also be essential to increase the number of high frequency polymorphic probes within this region to map more accurately their exchange points within individual families. Steps towards achieving this goal are being made by expanding the regions of cloned DNA by chromosome 'walking' ${ }^{36}$ and searching for other polymorphisms detected by the locus. Furthermore, the acquisition of completely new loci within Xp21 will provide additional information obtainable in these families and further define this region.

We would like to thank Drs M Bresnan and J Amos for obtaining family blood samples and human DNA, as well as all the families who took part in the study. We thank Professor P Pearson for the probes L1.28 and 754, Dr J-L Mandel for the probe C7, and Dr W Fenton for the probe OTC. We thank Drs Boyd, Craig, Francke, and Mohandas for the gift of both hybrid and human cell lines. We would also like to thank J Speer for help with OTC hybridisations. This work was supported by a grant from the Muscular Dystrophy Association of America.

\section{References}

${ }^{1}$ Boyd Y, Buckle VJ. Cytogenetic heterogeneity of translocations associated with Duchenne muscular dystrophy. Clin Genet 1986;29:108-15.

${ }^{2}$ Francke U, Ochs HD, deMartinville B, et al. Minor Xp21 chromosome deletion in a male associated with expression of Duchenne muscular dystrophy, chronic granulomatous disease, retinitis pigmentosa, and McLeod syndrome. Am J Hum Genet 1985;37:250-67.

${ }^{3}$ Baehner RL, Kunkel LM, Monaco AP, et al. DNA linkage analysis of X-linked chronic granulomatous disease. Proc Natl Acad Sci USA. 1986;83:3398-401.

4 Bartley JA, Patil S, Davenport S, et al. Duchenne muscular dystrophy, glycerol kinase deficiency, and adrenal insufficiency associated with a Xp21 interstitial deletion. $J$ Pediatr 1986;108: 1189.

5 Dunger DB, Davies KE, Pembrey M, et al. Deletion on the X chromosome detected by direct DNA analysis in one of two unrelated boys with glycerol kinase deficiency, adrenal hypoplasia, and Duchenne muscular dystrophy. Lancet 1986;ii:585-7.

${ }^{6}$ Davies KE, Pearson PL, Harper PS, et al. Linkage analysis of two cloned DNA sequences flanking the Duchenne muscular dystrophy locus on the short arm of the human X chromosome. Nucleic Acids Res 1983;11:2303-12.

7 Goodfellow PN, Davies KE, Ropers HH. Report of the committee on the genetic constitution of the $\mathrm{X}$ and $\mathrm{Y}$ chromosomes. Human Gene Mapping 8. Cytogenet Cell Genet 1985;40:296-352.

${ }^{8}$ Monaco AP, Bertelson C, Middlesworth W, et al. Detection of deletions spanning the Duchenne muscular dystrophy locus using a tightly linked DNA segment. Nature 1986;316:842-5.

9 Kunkel LM, Hejtmancik JF, Caskey CT, et al. Analysis of deletions in DNA from patients with Becker and Duchennec muscular dystrophy. Nature 1986;322:73-7.

${ }^{10}$ Fischbeck KH, Ritter AW, Tirschwell DL, et al. Recombinations with pERT 87 (DXS164) in families with X-linked muscular: dystrophy. Lancet 1986;ii:104.

${ }^{11}$ Dorkins H, Junien C, Mandel JL, et al. Segregation analysis of a marker localized Xp21.2-Xp21.3 in Duchenne and Becker muscular dystrophy families. Hum Genet 1985;71:103-7.

12 deMartinville B, Kunkel LM, Bruns G, et al. Localization of DNA sequences in region $\mathrm{Xp} 21$ of the human $\mathrm{X}$ chromosome: search for molecular markers close to the Duchenne muscular dystrophy locus. Am J Hum Genet 1985;37:235-49.

${ }^{13}$ Herva R, Kaluzewski B, de la Chapelle A. Inherited interstitial del (Xp) with minimal clinical consequences: with a note on the location of genes controlling phenotypic features. Am J Med Genet 1979;3:43-58.

14 Appel SH, Roses AD. The muscular dystrophies. In: Stanbury JB, ed. The metabolic basis of inherited disease. New York: McGraw-Hill, 1983.

15 Moser H. Duchenne muscular dystrophy: pathogenic aspects and genetic prevention. Hum Genet 1984;66:17-40.

16 Aldridge J, Kunkel L, Bruns G, et al. A strategy to reveal high-frequency RFLPs along the human X chromosome. Am J Hum Genet 1984;36:546-64.

17 Brunk C, Jones K, James T. Assay for nanogram quantities of DNA in cellular homogenates. Anal Biochem 1979;92:497-500

18 Southern EM. Detection of specific sequences among DNA fragments separated by gel electrophoresis. J Mol Biol 1975;98:503-17.

${ }^{19}$ Feinberg AP, Vogelstein B. A technique for radiolabelling DNA restriction fragments to high specific activities. Anal Biochem 1984;137:266-7.

20 O'Farrell P. Replacement synthesis method of labeling DNA fragments. Focus (Bethesda Research Labs) 1982;3:1-3.

21 Wieacker P, Davies KE, Cooke HJ, et al. Toward a complete linkage map of the human $\mathrm{X}$ chromosome: regional assignment of somatic cell hybrids. Am J Hum Genet 1984;36:265-76. 
22 Kunkel LM, Monaco AP, Middlesworth W, et al. Specific cloning of DNA fragments absent from the DNA of a male patient with an X chromosome deletion. Proc Natl Acad Sci USA 1985;82:4778-82.

${ }^{23}$ Ingle C, Williamson R, de la Chapelle A, et al. Mapping DNA sequences in a human $\mathrm{X}$-chromosome deletion which extends across the region of the Duchenne muscular dystrophy mutation. Am J Hum Genet 1985;37:451-62.

${ }^{24}$ Zatz M, Vianna-Morgante AM, Campos P, Diament AJ. Translocation $(X ; 6)$ in a female with Duchenne muscular dystrophy: implications for the localisation of the DMD locus. $J$ Med Genet 1981;18:442-7.

${ }_{25}$ Verellen-Dumoulin C, Freund M, deMeyer R, et al. Expression of an X-linked muscular dystrophy in a female due to translocation involving Xp21 and non-random inactivation of the normal X chromosome. Hum Genet 1984;67:115-9.

26 Botstein D, White RL, Skolnick M, Davis RW. Construction of a genetic linkage map in man using restriction fragment length polymorphisms. Am J Hum Genet 1980;32:314-31.

27 Hofker MH, Wapenaar MC, Goor N, et al. Isolation of probes detecting restriction fragment length polymorphisms from $\mathrm{X}$ chromosome-specific libraries: potential use for diagnosis of Duchenne muscular dystrophy. Hum Genet 1985;70:148-56.

${ }^{28}$ Rozen R, Fox J, Fenton WA, et al. Gene deletion and restriction fragment length polymorphisms at the human ornithine transcarbamylase locus. Nature 1985;313:815-7.

${ }^{29}$ Davies KE, Briand P, Ionasescu V, et al. Gene for OTC: characterization and linkage to Duchenne muscular dystrophy. Nucleic Acids Res 1985;1:155-65.

${ }^{30}$ Dean M, Park M, Le Beau MM. The human met oncogene is related to the tyrosine kinase oncogenes. Nature 1985;318:3858.

${ }^{31}$ Knowlton RG, Cohen-Haguenauer O, Van Cong N, et al. A polymorphic DNA marker linked to cystic fibrosis is located on chromosome 7. Nature 1985:318:380-2.

32 Wainwright BJ, Scambler PJ, Schmidtke J, et al. Localization of cystic fibrosis locus to human chromosome 7cen-q22. Nature 1985;318:384-5.

33 White R, Woodward S, Leppert M, et al. A closely linked genetic marker for cystic fibrosis. Nature 1985;318:382-4.

34 Drayna D, White $\mathrm{R}$. The genetic linkage map of the human $\mathrm{X}$ chromosome. Science 1985;230:753-8.

35 Schwartz DC, Cantor CR. Separation of yeast chromosomesized DNAs by pulsed field gradient gel electrophoresis. Cell 1984;37:67-75.

${ }^{36}$ Bender W, Arkam M, Karch F, et al. Molecular genetics in the bithorax complex in Drosophila melanogaster. Science 1983;221:23-9.

Correspondence and requests for reprints to Dr L M Kunkel, Division of Genetics, The Children's Hospital, 300 Longwood Avenue, Boston, Massachusetts O2115, USA. 